\section{ONOMÁVAEIN}

Revista semestral de lingüística, filología y traducción
PONTIFICIA UNIVERSIDAD

\title{
Constructing the Meaning of Cover and Spread: A Lexical-Constructional Approach ${ }^{1}$
}

\section{Carolina Rodríguez-Juárez}

Universidad de Las Palmas de Gran Canaria

España

\section{(c) $\odot$}

Carolina Rodríguez-Juárez: Instituto Universitario de Análisis y Aplicaciones Textuales, Universidad de Las Palmas de Gran Canaria, España | Correo electrónico: carolina.rodriguez@ulpgc.es 


\section{Abstract}

This research presents the results of the study of the verbs of position cover and spread as representative predicates of the subclass of verbs of putting something on (the surface of) something else and aims to examine the restrictions that regulate the subsumption process by means of which lexical structure can integrate into argument structure. In particular, we will deal with the integration of cover into the locatum subject construction, and of spread into the with-construction and provide a motivated account on the basis of external constraints such as metonymy, which regulate and license the integration of low-level lexical characterizations into higher-level constructional configurations. This meaning construction analysis will be done within the framework of the Lexical Constructional Model and will be complemented with a description of the interface mechanism which links meaning to syntactic structure following the analytical tools of Role and Reference Grammar.

Keywords: subsumption; constructions; Lexical-Constructional Model; Role and Reference Grammar. 


\section{Introduction}

This article presents the results of the study of the verbs cover and spread in terms of their semantic description and syntactic realizations and seeks to account for the factors that condition the fact that the predicate cover can participate in the locatum subject construction (Portraits covered the walls) alternating with the more basic with-construction (They covered the walls with portraits), whereas the verb spread, which is canonically used in the locative construction (He spread butter on the bread), alternates with the with-construction as in He spread the bread with butter. Much has been written about the different types of constructions that verbs can participate in and about how to account for the relationship between lexical and syntactic meaning. On the one hand, functional theories assume that lexical meaning conditions the morphosytantic structure of sentences and that this secondary relationship can be explained by means of a set of linking rules, whereas cognitive and constructional theories aim to explain this relationship from a different perspective and postulate that this relationship has to be conceived as a continuum from lexicon to grammar. Thus, for instance, a projectionist approach, such as Levin's (1993), presents a list of the alternations verbs can take part in by considering their similar semantic components together with their similar syntactic behaviour (1993: 17). Constructionist accounts like Goldberg's (1995, 2002, 2006), on the other hand, provide a detailed account of different constructions and propose a concept of construction that is very much in line with the one propounded by the Lexical Constructional Model ${ }^{2}$. However, these accounts, while providing relevant semantic and syntactic information which is undoubtedly beneficial for a study of this kind, fail to posit the cognitive constraints which regulate the integration of lexical characterizations into constructional configurations. Thus, this analytical problem has motivated our choice of the Lexical Constructional Model (henceforth LCM) as outlined in Ruiz de Mendoza (2013), Ruiz de Mendoza and Mairal (2007a/b, 2008) and Mairal and Ruiz de Mendoza (2006, 2008, 2009a/b) as the theoretical model on which we will base our analysis (for critical overviews see Butler, 2009, 2012, and Butler and Gonzálvez-García, 2014). In fact, it has been this concern about how to account for the relationship between syntax and meaning construction that has motivated the emergence of the LCM, since this model, in accordance with its cognitive orientation, and as a result of the special emphasis that it has placed on understanding the factors that constrain and regulate lexical-constructional integration (Mairal, 2015: 1), has sought to incorporate human cognitive mechanisms as motivating factors to account for the "systematic ways in which different kinds of conceptual pattern interact, thus yielding complex meaning representations" (Gonzálvez-García, 2015: 8).

The LCM explores the relation between lexicon and grammar by means of interface mechanisms that describe how lexical specifications in-

2 In Construction Grammar a construction is conceived as a "learned pairing of form with meaning or discourse function" (Goldberg, 2006: 5) in which "some aspect of its form or function is not strictly predictable from its component parts or from other constructions recognized to exist. In addition, patterns are stored as constructions even if they are fully predictable as long as they occur with sufficient frequency" (Goldberg, 2006: 5). The LCM agrees with this conception of construction but adds some criteria that must be fulfilled by a form-meaning pairing for it to be regarded as a construction: in a construction, "form consists of a morphosyntactic arrangement of elements" (Ruiz de Mendoza, 2013: 237); "productivity", that is, the form-meaning pairing is productive if "it gives rise to a pattern whose formal part can be realized by predicates that obey the requirements of the meaning part of the pairing" (Ruiz de Mendoza, 2013: 237); "bi-univocity", that is, the relationship between form and meaning is bi-univocal in the sense that "form cues for meaning and meaning is realized by form" (Ruiz de Mendoza, 2013: 237); and "replicability", which accounts for the fact that a construction can be strictly invariably reproduced by other competent speakers with all its meaning implications in similar contexts (Ruiz de Mendoza, 2013: 237-238) 
corporate the necessary input in order to trigger their unification into lexico-constructional configurations that will give rise to semantic interpretation. The LCM adopts and combines some of the descriptive, explanatory and analytical tools of both functionalist approaches and cognitive linguistics which have proved "to be effective to account for meaning construction and interpretation and for the formal realization of conceptual structure" (Ruiz de Mendoza, 2013) but incorporate their own methodological assumptions which try to overcome the weaknesses that can be found, for example, in functional projectionist theories, where the role of constructions in predicting morphosyntactic structure is ignored, and in constructional models, where the restrictions that constrain the unification process of a particular construction and a particular lexical entry are not explored.

The aim of this paper is to present a thorough analysis of the lexical-constructional integration process of the verbs cover and spread and to provide a motivated account in terms of the constraints which regulate the process by which the predicates cover and spread can participate in different constructions as the result of cognitive construal processes. This analysis will be conducted taking as a basis the theoretical and methodological assumptions of the LCM, which offers the necessary descriptive and explanatory tools in order to account for the limitations that have been observed in other theoretical approaches. In addition, this study will be complemented with an analysis of the consequences that the application of high-level cognitive re-construal processes such as metonymy may have in the syntax of these predicates by resorting to Role and Reference Grammar (RRG) since this model offers analytical tools which are not incompatible with the methodological assumptions of the LCM and serve to overcome the limitation that has often been pointed out as re- gards the current underdeveloped state in which syntax is in the LCM (see Butler and GonzálvezGarcía, 2014). The examples that I have analyzed are naturally-occurring example sentences withdrawn from the British National Corpus (BNC), some of which have been used to illustrate our research in the different sections of this paper ${ }^{3}$.

The paper is structured as follows. Section 2 deals with the semantic description of the predicates cover and spread and the constructions and alternations in which they participate. Section 3 provides a brief overview of the LCM focusing on the aspects of the model that are relevant to this study. Section 4 attempts to formulate the lexical and constructional configurations of each of the predicates under concern at the argument-structure level of description, and to explore their lexical-constructional interaction with the aim of finding out the constraints which motivate their different syntactic behaviour. Finally, section 5 includes the concluding remarks.

\section{Semantic and syntactic description of cover and spread}

In this section, a semantic description of the predicates cover and spread will be presented following three main sources. In the first place, I have consulted the paradigmatic organization of the lexicon presented by Faber and Mairal (1999), which motivated the choice of the two predicates that are being analyzed in this paper. Secondly, I have resorted to Levin's verbal class taxonomy, which offers a thorough description of verb classes organized by taking into account whether the predicates have similar semantic components and show similar syntactic behaviour (1993: 17). Finally, and in order to better understand the semantics of the verbs under scrutiny, I have made use of Fillmore's FrameNet database, which provides detailed semantic and

3 Specific reference to the corpus will be provided next to the examples that are mentioned in the text. 
syntactic information of predicates by presenting accurate definitions of the frames they belong to and their syntactic realizations. The final part of this section introduces the structural patterns and alternations in which these predicates participate in terms of Levin's distinctions (1993).

In Faber and Mairal's paradigmatic organization of the English lexicon into lexical domains and subdomains, the verbs cover and spread belong to the lexical domain "POSITION (To be in a particular state/condition/position without moving/changing)", which is structured into different subdomains, one of which is "to put something on the surface of something else", as exemplified by the verbal predicates cover and spread (1999: $284)^{4}$. These verbs fall below other three higher levels or subdomains which are described as follows (Faber and Mairal, 1999: 284):

1. To be in a particular state/condition/position, without moving, changing (STAY, LIE)

1.1. to cause somebody or something to stay in a particular state/condition/position (KEEP, MAINTAIN)

1.1.1. to cause somebody or something to $\mathrm{BE}$ in a particular place/position (PUT, PLACE)

1.1.1.1. to put things together (JOIN, ATTACH)

1.1.1.2. to put many things together (POOL)

1.1.1.3. to put something around something else (WRAP)

1.1.1.4. to put something on (the surface of) something else (COVER/SPREAD)
1.1.1.4.1. To cover something with something to protect it / make it more attractive (PAINT/ COAT)

1.1.1.4.2. To cover somebody/something so that it cannot be seen (ENSHROUD/CLOAK)

In Levin's verbal class organization (1993), the predicates under concern are both classified into the general verb class of Verbs of Putting (1993: 111), which is subdivided into ten different subclasses. Spread belongs to the subclass of Spray/ Load verbs (Levin, 1993: 118-19), which are related to covering surfaces and putting things into containers ${ }^{5}$, and which have been largely investigated $^{6}$. The following sentences show representative examples of this verb class as provided by Levin (1993: 118):

(1) Jessica loaded boxes onto/into/under the wagon.

(2) Jessica sprayed paint onto/under/over the table.

Cover is said to belong to the subclass of Fill verbs, which typically describe the resulting state of a location (area) as a consequence of putting something on it or in it (Levin, 1993: 120). The following examples taken from Levin illustrate this verb subclass (1993: 119):

(3) Leslie staffed the store with employees.

(4) Leigh swaddled the baby with blankets.

4 In Appendix I, I have attempted to provide an exhaustive list of verbs which belong to the lexical subdomain of "to put something on (the surface of) something else" (Level 1.1.1.4).

5 Pinker gives a fine subdivision of Spray/Load verbs into five classes. In this subdivision, spread is presented as belonging to the slather-class, which includes predicates that "show simultaneous forceful contact and motion of a mass against a surface” (Pinker, 1989: 126-127, in Goldberg, 1995: 176).

6 See Levin (1993: 117) for an exhaustive list of references of research papers conducted on Spray/Load verbs, not only in English but also in other languages. 
FrameNet online database of English, based on Fillmore's Frame Semantics ${ }^{7}$, provides a detailed semantic description of the predicates cover and spread by offering the semantic and syntactic combinatory possibilities of each word in each of its senses. In this sense, they describe the frame each lexical unit belongs to and present a lexical entry report which includes the frame elements for each word sense, their syntactic realization and the syntactic patterns in which these frame elements may occur, together with an annotation report which incorporates annotated corpus-based examples. Thus, in Fillmore's Frame Semantics analysis, cover and spread are placed within the Filling frame, which includes verbs that relate to filling containers and covering areas (referred to as Goals) with some thing, things or substance (the Theme), with the result of the area being crucially affected.

(5) She broke off a piece of baguette, spread it (Goal) with butter and jam (Theme), ... (FrameNet)

(6) Samantha covered the table (Goal) with flowers (Theme) to please her mother. (FrameNet)

Cover is additionally included in the frame Adorning, where a Location and a Theme display a static (primarily spatial) relationship between them. In this frame, the Location (the table) refers to the entity in relation to which the Theme's (flowers) spatial arrangement is described, and the Theme is conceived as the entity which stands in a particular spatial relation with respect to a Location:

(7) Flowers (Theme) covered the table (Location). (FrameNet)
All the verbs used statically in the frame Adorning can also occur in the frame Filling, producing pairs such as (6) and (7), which implies that Adorning verbs can also occur in the frame Filling but not the other way around; that is, cover (stative verb as in (7)) can appear as a non-stative verb (as in (6)); however, spread cannot appear in the Adorning frame since it does not have a stative counterpart ${ }^{8}$, but it is also included in the Dispersal frame in which an entity (Agent or Cause) disperses or scatters another entity or entities (Individuals) from a Source (perceived as a relatively confined space) to a Goal area which is conceived as being a broader space than the source. In these cases, the Goal area is not necessarily perceived as being completely affected by the action of the verb.

(8) She spread butter (Individual) on a fresh bread roll (Goal area). (FrameNet)

A careful analysis of the examples provided for the verbs cover and spread in their corresponding verb classes and semantic frames reveals that these verbs display different options of argument realization thus participating in different argument alternations (Levin and Rappaport, 2005: 17) where the most basic patterns can alternate with other frames in, what Levin calls, "a near-paraphrase relationship" (1993: 60). Observe, for instance, examples (5) and (8) for spread and examples (6) and (7) for cover.

As far as the predicate spread is concerned, Levin includes it within the group of predicates which exhibit the Locative alternation, an umbrella term which includes other types of alternations related to verbs of putting (and also removing verbs) which involve a change in the position of the arguments within the verb phrase but do

7 The FrameNet Project is developed by the International Computer Science Institute in Berkeley, California, and is based on the theory of meaning called Frame Semantics, which derives from the work of the late Charles J. Fillmore and colleagues (Fillmore, 1976, 1977, 1982, 1985; Fillmore and Baker, 2010). See: http://www.icsi.berkeley.edu/ framenet for details.

8 Except when a change in valency is observed and the verb is used intransitively as in Butter spreads easily. 
not imply a change in the transitivity of the verb (1993: 49-55). In particular, within this alternation, spread participates in the so-called spray/load alternation in which a locative variant (example (9)) alternates with a with-variant (example (10)) (Levin, 1993: 50-51). In this alternation, the affected arguments are examples of the locatum argument (which refers to the entity whose location is changed, i.e. the "transferred stuff" (Levin and Rappaport, 2005: 17)) and the location argument (which refers to the surface) ${ }^{9}$, and they can be both presented either as the direct object of the verb or as the object of an appropriate preposition:

(9) He cut another slice of bread and spread the butter (Locatum) on it (Location) from edge to edge very carefully. (BNC G3P W_misc)

(10)Spread the cake (Location) with cream (Locatum). (BNCABB W_instructional)

In the spray-load alternation, we distinguish two constructions: the locative construction, represented by example (9), where the Locatum is presented as the direct object of the verb and the Location as the object of a preposition (on, over, across, etc. $)^{10}$, and the with-construction, exemplified in (10), in which these two arguments are presented the other way around and the Locatum is typically introduced by the preposition with ${ }^{11}$.

When the location argument, that is, the surface, is expressed as the direct object (example (10)) in the with-construction, it shows what has been called the holistic effect or affected interpretation, in the sense that surface is understood to be in some way completely affected by the action" $^{12}$, or, as Fillmore claims, the area is "affected in some crucial way" since it seems to be completely covered by another entity. The location, however, does not necessarily have to receive such an interpretation when it is expressed as the object of a preposition in the locative construction. In example (9), for example, it is the phrase "from edge to edge" that introduces the idea that the area was completely affected by the action of the verb.

The predicate cover, on the other hand, shows an alternation between its basic pattern represented by the with-construction (example (11)), and Levin's locatum subject construction (1993: 81), exemplified in (12). The locatum subject construction involves a change in the number of phrases that are found with the verb but, as in the locative construction, the transitivity of the verb is not affected. In this case, in which Fill verbs can participate, the shift of phrases results in what Levin calls "'Oblique' subject alternations" (1993: 79, 81), since the argument of the verb expressed in the with-phrase is alternatively expressed as an oblique subject.

(11)Cover old glass in doors and low windows with safety film. (BNC CH1 newsp_tabloid)

(12) Portraits of ancestors covered the walls. (BNC FPF W_fict_prose)

Table 1 summarises the different constructions in which the predicates cover and spread can be found, which will be explored from the point of view of meaning construction in the next sections of this paper.

9 The terms "locatum argument" and "location argument" were coined by Clark and Clark in their study of verbs zerorelated to nouns (1997) (cited in Levin, 1993: 50).

10 These examples are related to the Dispersal frame introduced by Fillmore

11 Levin provides a list of verbs that, especially when they involve covering the surface with clothes or cloths, allow the argument to be introduced by the preposition in, alternating with with: bathe, blanket, coat, cloak, cover, deck, festoon, garland, line, robe, shroud, swaddle, swathe, veil, wreathe (1993: 120).

12 The holistic effect was first observed by Anderson (1971); however, it has also received much criticism and Levin argues that "some studies have shown that the notion 'holistic' is not always accurate" (1993: 50 and 118). 
TABLE 1

Cover and spread: constructions and structural patterns

\begin{tabular}{|c|c|c|c|}
\hline CONSTRUCTIONS & PATTERNS & COVER & SPREAD \\
\hline $\begin{array}{l}\text { Locative } \\
\text { construction }\end{array}$ & $\begin{array}{l}\mathrm{NP} 1+\mathrm{V}+\mathrm{NP} 2+\mathrm{PP}\left(\mathrm{NP}_{3}\right) \\
\text { Locatum argument (NP2) } \\
\text { (entity whose location } \\
\text { is changed) + Location } \\
\text { argument (NP3) (surface) }\end{array}$ & $\begin{array}{l}\text { *... the other elephants } \\
\text { from the herd covered } \\
\text { branches and leaves on } \\
\text { the corpse... }\end{array}$ & $\begin{array}{l}\text { He cut another slice of } \\
\text { bread and spread the } \\
\text { butter on it from edge to } \\
\text { edge very carefully. (BNC } \\
\text { G3P W_misc) }\end{array}$ \\
\hline With-construction & $\begin{array}{l}N_{1}+V+N P_{3}+P P\left(N_{2}\right) \\
\text { Location }\left(N_{3}\right)+\text { Locatum } \\
\left(N P_{2}\right)\end{array}$ & $\begin{array}{l}\text { Cover old glass in doors } \\
\text { and low windows with } \\
\text { safety film. (BNC CHI } \\
\text { newsp_tabloid) }\end{array}$ & $\begin{array}{l}\text { Spread the cake with } \\
\text { cream. (BNC ABB W_ } \\
\text { instructional) }\end{array}$ \\
\hline $\begin{array}{l}\text { Locatum subject } \\
\text { construction }\end{array}$ & $\begin{array}{l}N P_{2}+V+N P_{3} \\
\text { Locatum }\left(N_{2}\right)+\text { Location } \\
\left(N_{3}\right)\end{array}$ & $\begin{array}{l}\text { Portraits of ancestors } \\
\text { covered the walls. (BNC } \\
\text { FPFW_fict_prose) }\end{array}$ & *Butter spread the toast. \\
\hline
\end{tabular}

\section{Brief overview of the Lexical Cons- tructional Model}

So far we have based our discussion of the verbal predicates cover and spread on a combination of work by Faber and Mairal (1999), Levin (1993, 2005) and Fillmore's frame semantics which have shed important light as regards the verb classes these predicates belong to, their semantic properties and the patterns of argument realization that they show. However, as Levin and Rappaport claim, "verb classes themselves are epiphenomenal" and "there are more basic elements of meaning which determine argument realization" (2005: 18). It is our concern in this section to find out the aspects of meaning which are responsible for their "multiple argument realizations", i.e. their ability "to appear in a variety of syntactic contexts" which are often accompanied by variations in meaning (Levin and Rappaport, 2005: 18). In doing so, we have adopted a constructional approach taking as a basis the explanatory apparatus of the Lexical Constructional Model, which will help us explore and explain why spread shows the locative spray-load alternation (Spread the cream on the cake / Spread the cake with cream) whereas cover does not, and similarly, why cover can participate in the locatum subject construction alternating with the with-construction (They covered the walls with portraits / Portraits covered the walls) whereas spread cannot. Let us now present those aspects of the model which are relevant for the present research and which will be later used in our account of the description of the distinctive features of the predicates cover and spread.

The Lexical Constructional Model (LCM) is "a usage-based account of language-based meaning construction" (Ruiz de Mendoza y Galera, 2014: 3) at all descriptive levels. The general structure of the model recognizes four levels of meaning construction and provides a descriptive apparatus for each layer specifying the conditions to combine representations within and across levels (Ruiz de Mendoza y Galera, 2014: 3). The argument-structure level (level 1 ) deals with basic predicate-argument relationships which are the building blocks of meaning construction and take the form of lexical and constructional templates. Lexical templates are low-level nonsituational propositional representations of the event structures of predicates (for example, kill $(x, y)$, walk $(x)$ ), whereas constructional templates are argument-structure high-level non-situational propositional representations such as the resultative or the caused-motion construction, which are exemplified as $X$ causes $Y$ to become $Z$ and $X$ causes $Y$ to move to $Z$, respectively (Ruiz de 
Mendoza, 2013: 25, and Ruiz de Mendoza and Galera, 2014: 31). The implicational level (level 2) explains non-illocutionary structure related to lowlevel situational features of linguistic meaning such as the level-2 implicational construction Wh-'s been $V$-ing Y?, where Who's been sleeping in my bed? implies that the fact that someone has been indeed sleeping in my bed bothers me (Ruiz de Mendoza, 2013: 23, 25). The illocutionary level (level 3) deals with illocutionary structures related to high-level situational inferences that are associated with illocutionary structures such as I won't X! as in I won't do that!, which generally invokes the illocutionary scenario of refusals (Ruiz de Mendoza, 2013: 23, 25). Finally, the discourse level (level 4) copes with discourse structure and high-level non-situational cognitive models such as the discourse structure construction $X$ Let Alone $Y$ used to refer to two improbable states of affairs where the second is even less unlikely to occur, such as in I won't eat that garbage, let alone pay for it (Ruiz de Mendoza, 2013: 2, 24-25).

In terms of the explanatory tools of the LCM, the notion of subsumption is used as an example of a basic meaning construction process that has to do with the integration of conceptual structure across levels of description ${ }^{13}$. Subsumption is a cognitive operation which is used to explain the interaction of meaning representation across the four different levels of description and which consists in building lexical structure into argument structure. A recurrent example in the LCM literature is the subsumption of the verbal predicate laugh into the caused-motion construction as in The child was laughed out of the school yard (Ruiz de Mendoza and Mairal, 2008; Ruiz de Mendoza, 2013: 26) ${ }^{14}$. The subsumption process is regulated by a set of internal and external constraints. Internal constraints regulate the conceptual compatibility of lexical predicates and argument-structure configurations ${ }^{15}$, whereas external constraints regulate the susceptibility of a lexical structure to be re-construed so that it can integrate into a non-lexical construction (Ruiz de Mendoza, 2013: 27). The former are not based on construal and act as blocking factors, whereas the latter are based on construal and act as licensing factors on lexical-constructional subsumption through high-level cognitive operations such as metaphor and metonymy, which motivate re-construal processes ${ }^{16}$.

We will be using the LCM theoretical background to account for the motivaton behind the different semantic and syntactic behaviour of the verbal predicates cover and spread. However, since the LCM is a meaning construction model and does not account for the way in which the linking between syntax and semantics takes place, we will complement this analysis with some of the analytical descriptive tools of the explanatory apparatus of Role and Reference Grammar (RRG) (Van Valin and Lapolla, 1997; Van Valin, 2005) in order to explain the interface mechanisms which link meaning to syntactic structure.

13 Another meaning construction process that the LCM postulates is cued inferencing or cueing by means of which implicit conceptual structure is activated through inferential mechanism on the basis of textual and contextual cues (Ruiz de Mendoza, 2013: 25-26). For a complete account of cueing see Ruiz de Mendoza (2011) and (2013).

14 The integration of conceptual structure can take two other forms apart from subsumption: amalgamation, which accounts for level-internal integration, e.g. the active and passive realizations of the transitive construction (for a practical example of amalgamation, see Galera, 2012) and saturation, which "realizes variables from either idiomatic or non-idiomatic constructional characterizations through lower-level representations" (Ruiz de Mendoza, 2013: 27).

15 A typical example used in the literature to exemplify internal constraints is The Lexical Class Constraint which shows that "all members of the same class or subclass are in principle compatible with a given constructional configuration" (Galera 2012: 170). Thus, a lexical predicate like destroy cannot occur in the inchoative argument structure construction (*The city destroyed) in spite of its semantic similarity with the predicate break, which can take part in that construction (The vase broke) due to the fact that they belong to different classes since destroy is an existential predicate that fits into the class "cessation of existence" whereas break is a change-of-state predicate belonging to the class of "break" verbs (Mairal y Ruiz de Mendoza 2009: 190, Galera 2012:170-171, Ruiz de Mendoza and Galera 2014:35).

16 For a thorough account of internal and external constraints, see Ruiz de Mendoza (2013). 
Butler and Gonzálvez-García acknowledge that syntax is currently underveloped in the LCM:

The architecture of the LCM fits in nicely with the premise that syntax is by and large motivated by semantic factors. At this stage, an important observation is in order. In the LCM, syntax remains underdeveloped in comparison to RRG, as noted in Butler (2009a). In any case, it is clear that syntax is not autonomous from semantics in the LCM. (2014: 215)

Gonzálvez-García (2015) goes one step further and predicts that it can be assumed that the LCM will adopt a position in consonance with RRG, which has led us to incorporate RRG analytical tools such as Aktionsart ascription and thematic and macro-role assignments in our analysis in order to describe syntactic phenomena which results from higher-level factors that directly motivate and influence constructional realization.

\section{Semantic and syntactic representa- tion of cover and spread}

The linking algorithm that the Lexical Cosntructional Model (LCM) presents in the development of the presentation of lexical templates is a development of the logical structures of Role and Reference Grammar (RRG), which represent the semantic and argument structure of predicates. These lexical templates are made up of two modules: a semantic module, which "expresses the semantic and pragmatic parameters that underlie predicate meaning" (Ruiz de Mendoza y Mairal,
2008: 8) and that specifies lexical functions that have shown to be universally valid (Mel'čuk, 1989; Mel'čuk and Wanner, 1996) ${ }^{17}$ and an Aktionsart module, based on RRG logical structures, which includes semantic primes provided in boldface (e.g. do') and variables ( $x$, $y$ and $z$ ), which are filled in by lexical items from the language that is being analyzed, and that are represented in normal font (Van Valin, 2005: 45) ${ }^{18}$. In the current research, only the Aktionsart module will be explored.

In order to be able to analyze the predicates cover and spread at the argument-structure level of description in terms of Aktionsart ascriptions (which offer the information needed to be able to formulate the logical structures and constructional templates of these predicates), I have followed the theory of verb classes presented in the work of Valin and Lapolla (1997) and Van Valin (2005), which at the same time relies on the lexical decomposition approach in terms of the Aktionsart distinctions proposed in Vendler (1967 [1957]) and the decompositional system put forward by Dowty (1979). Thus, these verbs should be both ascribed to the class causative accomplishment, which can be decomposed into the following semantic parameters: + causative, static, - dynamic, + telic, + duration,-punctual and which can be paraphrased as x CAUSES y and $z$ to BECOME be-on'. In this sense, the semantic structure and argument structure of these predicates in these constructions can be represented by using the same complex logical structure (13) for both predicates, in which there is an activity predicate (indicating the causing action, do'), and an accomplishment, which can be said to "involve both a process that takes place over time [that

17 In 2008, the LCM proposed a "reconversion" of the inventory of lexical functions by incorporating the set of qualia postulated by Pustejovsky (1995) and which belongs to the third level of representation of the generative lexicon (Mairal and Ruiz de Mendoza 2008: 147).

18 For example, the activity predicate drink is represented as do' ( $\mathrm{x}$, [drink' (x)]), where the variable $\mathrm{x}$ will be filled in by lexical items belonging to different languages: (do' (John, [drink'(John)]).

19 The holistic nature of the verb cover ("to put on and occupy that surface completely") implicitly shows telicity, a property typically linked to this holistic interpretation, as can be derived from the fact that it is possible to use adpositions such as "in 5 minutes" (He covered the bed in five minutes), which indicates completion and focuses on the terminal point of the event; telicity, on the contrary, is not a semantic parameter associated to activities, which are atelic in nature. 
is why they have duration and are not punctual], and an inherent endpoint of the process leading to the resulting state of affairs [that is why they are telic ${ }^{19}$ ]" (Van Vallin and Lapolla, 1997: 43), both of which are linked by the operator-connective CAUSE. I have also provided the ascription of thematic relations to the arguments (effectors, goals and themes):

\section{(13) $\left[\mathbf{d o}^{\prime}\left(\mathrm{x}_{\text {EFFECTOR' }}, \varnothing\right)\right]$ CAUSE $\left[\mathrm{BECOME}\right.$ be-on' $\left(\mathrm{y}_{\text {GOAL'}}\right.$ $\left.\left.\mathrm{Z}_{\text {THEME }}\right)\right]$ \\ $\mathrm{He}(\mathrm{x})$ cut another slice of bread and spread the butter ( $z$ ) on it (y) from edge to edge very carefully. (BNC G3P W_misc) \\ ... the other elephants from the herd $(x)$ cove- red the corpse $(y)$ with branches and leaves (z). (BNC G2V W_pop_lore)}

This logical structure could be read as follows: the first argument of an activity $x$, the effector, does something that causes the theme, $z$, to become to "be on y (Goal)". That is, the effector (who can be described as the doer of an action) uses the theme (z) (which corresponds to the second argument of a two-place state predicate of location (predicate' $(y, z))$ ), which is the participant that is placed, moved, etc., in order to cause the theme to become 'be on y', where ' $y$ ' is the Goal (i.e. the first location argument of the two-place state predicate of location (predicate' $(y, z))$ ).

The question, then, to be answered is the following: if the two predicates share the same logical structure, how can we explain and represent the fact that cover can occur in the withconstruction alternating with the locatum subject construction, whereas spread alternates in both, the locative and the with-constructions but does not participate in the locatum subject construction?

\subsection{Constructing the meaning of spread}

As we have already mentioned, spread shows a canonical form (He spread the butter on the bread) related to the locative construction, in which the verb spread describes the action of dispersing entities over a surface with no further implications of the surface being fully or completely affected by this action. However, the appearance of spread in the with-construction (He spread the bread with butter) implies that the surface is somehow completely affected by the spreading and should be interpreted as case of subsumption which shows that the predicate spread has been re-construed in such a way that it can be integrated into the with-construction. This fusion is conditioned by means of an external constraint that regulates a metonymic re-construal process which implies the metonymic shift RESULT FOR ACTION. In this case, the action of spreading is envisaged in terms of "covering" in the sense that partially or fully covering an area or a surface is the result of distributing items or a substance over a surface. Therefore, this metonymy lends conceptual prominence to the surface and its resultant state and licenses it (the surface) as a non-congruent object, which, as a consequence, requires the canonical semantic object to be realized as a non-congruent instrument introduced by the preposition with.

We will now use the RRG analytical tools to describe, at the syntactic level, the consequences of the higher-level metonymic process described so far. Thus, in the case of spread, the two constructions that derive from the same logical structure can be accounted for by different macrorole assignment possibilities to Undergoer ${ }^{20}$. In fact, as Van Valin and LaPolla suggest (1997: 145), in these cases in which there are two non-

20 In RRG, the macroroles Actor and Undergoer are generalizations of the different types of sematic roles and serve to link the semantics of predicates to its syntax in the interface mechanism. They are associated with the two primary arguments of a predication (both transitive and intransitive), and correspond to what has traditionally been called "subject" and "object" in syntactic terms, where Actor is the most agent-like argument and Undergoer the most patient-like argument. Each macrorole, additionally, subsumes specific thematic realtions (Van Valin, 2005: 60). 
actor arguments, the speaker can select one argument over the other as "being the primary affected participant" in the state of affairs and as a result code it as the Undergoer. Moreover, they argue that the selection of the argument that is candidate for the function of Undergoer "must be made at the outset of the mapping, as everything else depends upon the macrorole assignments either directly or indirectly" (1997: 338).

Thus, if we focus on the relevant part of the LS underlying this construction, CAUSE [BECOME be-on' $(y, z)]$, different macrorole assignment possibilities to Undergoer can be accounted for following the selection principles of the the ActorUndergoer Hierarchy (A-UH) (see figure I below), which are at the same time directly connected with the rules for argument-marking prepositions as proposed in Van Valin and LaPolla (1997: 376ff.).

In the default linking, which is represented by the locative construction (He spread the butter on the bread), the first argument of the acti- vity predicate is assigned the MR Actor and the theme becomes the Undergoer, following the Actor-Undergoer selection principle that states that the rightmost argument will be the Undergoer $^{21}$. There is also a third non-macrorole argument (the first argument of a locative predicate), which is marked by the locative preposition on/ over (Oblique Core Argument, OCA).

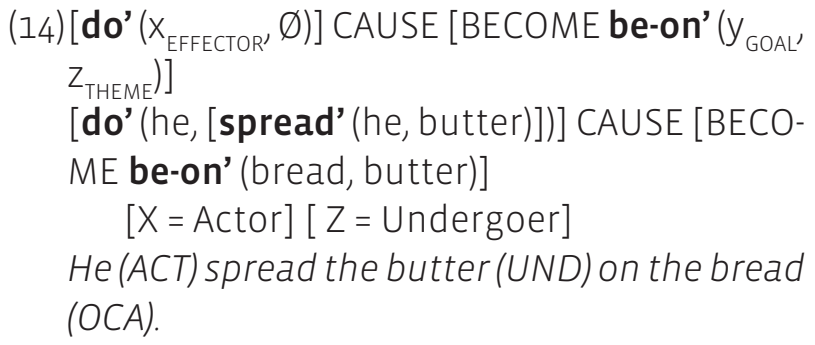

In the marked linking, which is represented by the with-construction (He spread the bread with the butter), since the default choice for Undergoer, which in RRG terms is described in the A-U Hierarchy as "the lowest ranking argument in LS (default)" (Van Valin, 2005: 126), is not selected as

\section{FIGURE 1}

Selection principles of the Actor-Undergoer Hierarchy (Van Valin, 2005: 126)

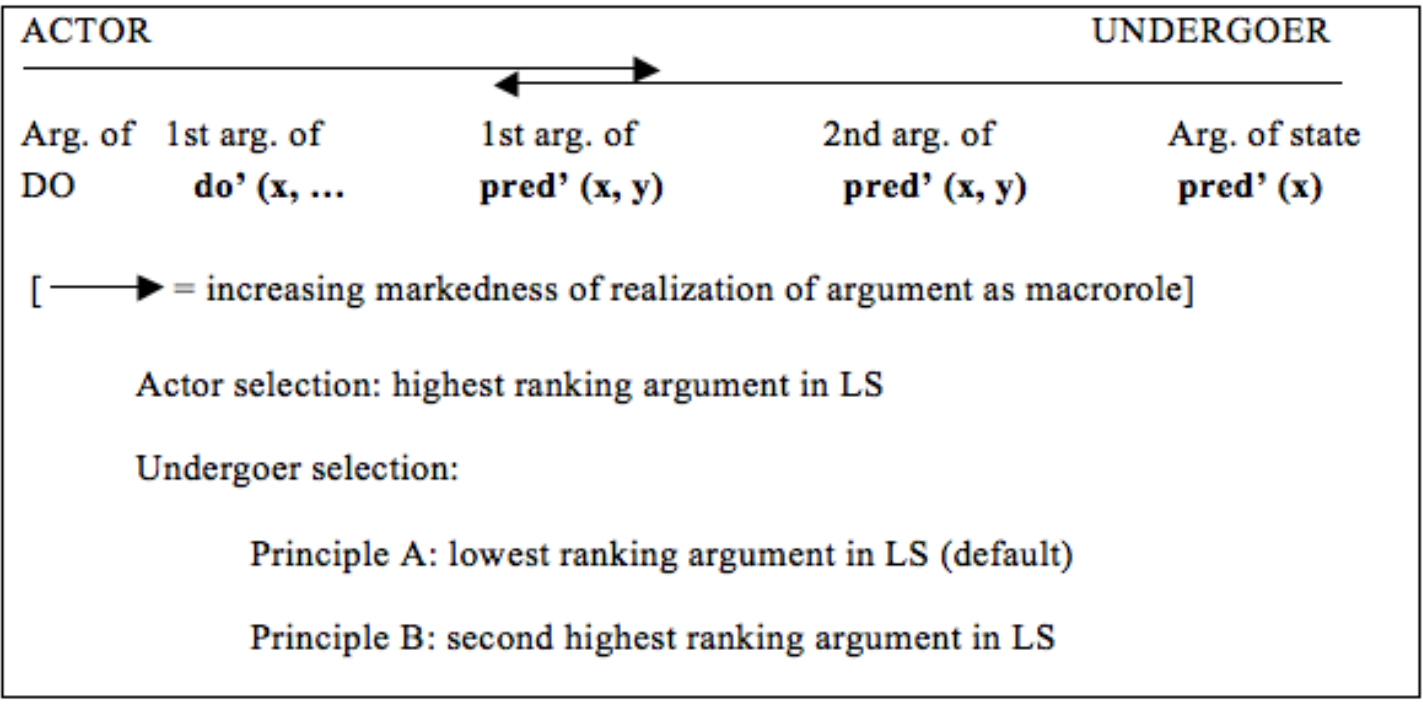

21 In the default situation, the leftmost argument will be the Actor and the rightmost argument will be the Undergoer (Van Valin, 2005: 61). 
such, it has to be marked by with as an oblique argument, as a result of the rule for assigning with in English, whereas the other potential argument (y), the goal, is selected as Undergoer ${ }^{22}$.

$$
\begin{aligned}
& \text { (15) }\left[\mathbf{d o}^{\prime}\left(\mathrm{X}_{\text {EFFECTOR' }} \varnothing\right)\right] \text { CAUSE [BECOME be-on' }\left(\mathrm{y}_{\text {GOAL'}^{\prime}}\right. \\
& \left.\left.\mathrm{Z}_{\text {THEME }}\right)\right] \\
& \text { [do' (he, [spread' (he, butter)])] CAUSE [BECO- } \\
& \text { ME be-on' (bread, butter)] } \\
& {[\mathrm{X}=\text { Actor }][\mathrm{Y}=\text { Undergoer }][\mathrm{Z}=\text { oblique }} \\
& \text { argument] } \\
& \text { He (ACT) spread the bread (UND) with the but- } \\
& \text { ter (OCA). }
\end{aligned}
$$

Thus, the marked Undergoer assignment is motivated by the fact that in the with-construction the surface $(y)$ is perceived as being fully affected by the spreading, and the cognitive prominence lent to this entity is reflected in the syntax in the marked assignment of Undergoer to the surface-argument.

However, there is a further situation that has to be taken into account. Consider the following example, in which only the locative construction is possible:

(16)On the first morning, I (ACT) spread books (UND) on their huge kitchen table and started to cross refer. (BNC HGF W_fict_prose)

The fact that there seems to be a constraint in the alternation possibilities of the predicate spread could be attributed to internal selectional restrictions which only allow the two Undergoer assignment possibilities to exist if the referent of the theme is a mass noun relating to a soft substance; if the referent is a countable noun such as magazines, a sheet of paper, books, paperbacks, maps, etc. (examples from the BNC), only the locative construction is possible. Thus, the following internal selectional constraint can be formulated: if the theme refers to a countable noun [+ physical, + solid], the macrorole Undergoer must be assigned to $z$; if not, that is, if the theme is a mass noun [+ physical, -solid, + mass], two different possible assignment possibilities to Undergoer can take place:

\section{(17) [do'(they, ['spread (they, maps)])] CAUSE [BE- COME be-on'(floor, maps)]}

Selectional restriction: if theme $=+$ solid, only $\mathrm{Z}=$ Und

$$
\text { [X = Actor] [ if }(Z=+S O L I D), Z=\text { Undergoer }]
$$
They (ACT) spread the maps (UND) on the floor. (BNC GUV_humanities_arts)

(18) [do' (he, [spread' (he, butter)])] CAUSE [BECOME be-on' (bread, butter)]

Selectional restriction: if the theme is [+ physical, -solid, + mass], two different assignment possibilities to Undergoer: either $Z=$ Undergoer (default linking) or $Y=$ Undergoer (marked linking)
Deafult linking:
[X = Actor $]$ [ $\mathrm{Z}=$ Undergoer $]$
He (ACT) spread the butter (UND) on the bread (OCA).
Marked linking:
[X = Actor $][\mathrm{Y}=$ Undergoer $][\mathrm{Z}=$ oblique argument]
He (ACT) spread the bread (UND) with the butter (OCA).

Thus, we can see that the re-construed form of spread, which is related to the with-construction, only shares some of the semantic properties of

22 The rule for assigning the preposition with in English is presented in Van Valin as follows: "Assign with to non-MR $b$ argument if, given two arguments, $a$ and $b$, in a logical structure, with (1) both as possible candidates for a particular macrorole and (2) a is equal or higher (to the left of $b$ ) on the AUH, b is not selected as that macrorole" (2005: 114). The important thing to note about this rule, as opposed to the rules for the prepositions to and from, is that it does not refer to a specific argument position or positions in logical structures but to the macrorole assignment phase of the linking procedure and that the two arguments in question have to be candidates for the same grammatical status. 
cover in the sense that in these cases the verb spread must take a semantic object that is associated to entities which are substances or masses. The meaning of cover, however, is larger in the sense that the covering can be done by using either substances or concrete entities.

\subsection{Constructing the meaning of cover}

In the same way as spread can be used congruently with a locative construction and non-congruently in the with-construction emulating the constructional properties of cover, cover can be used congruently in the with-construction (Elephants covered the corpse with branches) and non-congruently in the locatum subject construction (Portraits of ancestors covered the walls). The basic scenario of cover is causal in the sense that it shows an agent or natural or non-human force that causes a surface to be covered by using something, as illustrated by the with-construction (Elephants covered the corpse with branches). However, this basic scenario can be depicted from a different perspective in which the covering action is not causal but presented as a static situation in the locatum subject construction (Portraits covered the walls). Therefore, the scenario that the predicate cover is representing in the locatum subject construction is metonymic for (or stands for) the basic scenario in which there is an agent or natural cause implied in the covering. Thus, metonymy here is regulating another example of an external constraint based on construal and is acting as a licensing factor which allows us to reinterpret the basic scenario of cover as non-causal and as an instance of re-construal in which the entity used to cover the surface in the covering scenario is given conceptual prominence, and, as a result, used non-congruently as the subject of the sentence (the real causer of the action is not specified in this construction as a result of its conceptual backgrounding).

Let's now complete this motivated analysis of constructional realization with an analysis in terms of RRG different macrorole assignment possibilities that will describe the syntactic structure that results from this high-level metonymic process. In the linking algorithm of cover, there also seem to be two potential macrorole candidates, but this time for Actor and not for Undergoer, as was the case with the predicate spread. In fact, the analysis of the preposition with is not related to the general rule for assigning with in English, but it corresponds to the instrumental use of this preposition, in which "with marks a potential actor which is not selected as actor" (Van Valin and LaPolla, 1995: 378) ${ }^{23}$.

Another difference with spread is that in the examples with the predicate cover we find the presence of a causal chain in which there are two effectors ( $x$ and $y$ ) that are potential Actors in terms of the AUH: the first effector, the instigator, acts on the secondary implement-effector, the instrument, which in turns acts on the theme (Van Valin and LaPolla, 1995: 378-379). An effector describes "a participant that brings something about, but there is no implication of its being volitional or the original instigator" (Van Valin and LaPolla, 1995: 118). The first effector is the doer of the action and the second effector-argument is conceived as an instrument (and as a result used by another entity to cause something) and not as "the original instigator", i.e. it is not perceived as a real agent or natural force responsible for

23 Let's illustrate the instrumental use of the preposition with the verbal predicate cut. The logical structure of cut includes two effectors that are two potential Actors in the terms of the Actor-Undergoer Hierarchy: the doer of the action and the implement/instrument used in the cutting. If the first effector (the doer) is selected as Actor, we have a sentence like Tom cut the bread with the knife in which the second potential Actor (i.e. the knife) has to be coded as a with-phrase in which the preposition with is marking a potential Actor that has not been seleceted as such. However, if the second implement-effector is selected as Actor we will have a sentence like The knife cut the bread in which the first effector is left unspecified (Van Valin and LaPolla, 1995: 378) 
the causing action, as is the case with the first effector.

The first assignment possibility shows that the first effector $(x)$ in the causal chain becomes Actor, and the second effector (y) will have to be realized by a non-macrorole core argument marked by the preposition with.

(19)Actor assignment to first effector: $\left[\mathbf{d o}^{\prime}(x,[\ldots])\right]$ CAUSE $\left[\left[\ldots\right.\right.$ do' $\left.^{\prime}(y,[\ldots])\right]$ CAUSE $[B E-$ COME pred' $(z, y)]]$

[do' (elephants, [use' (elephants, branches])] CAUSE [[do'(branches, [cover'(branches, corpse])]

CAUSE [BECOME be-on' (corpse, branches)]] [ $\mathrm{x}=$ Actor $][\mathrm{z}=$ Undergoer $]$ ... the other elephants (ACT) covered the corpse (UND) with branches (OCA). (BNC G2V W_ pop_lore)

The other assignment possibility favours the assignment of Actor to the second effector-instrument-implement in the causal chain resulting in constructions like Portraits of ancestors covered the walls, which are associated to the locatum subject construction, in which Fill verbs can participate and in which the argument of the verb expressed in the with-phrase is alternatively expressed as an oblique subject with no idea of causality or volition implied. Thus, in the template we have to include the symbol for the empty set $(\varnothing)$, which represents the argument in this causal chain that has been left unspecified. As a consequence, in terms of macrorole assignment, we must find another candidate for Actor, which will be the first argument of the second activitiy do' $^{\prime}(y,[\ldots])$ in the chain:
(20)Actor assignment to second effector:

$\left[\right.$ do' $\left.^{\prime}(x,[\ldots])\right]$ CAUSE $[[\ldots$ do' $(y,[\ldots])]$

CAUSE [BECOME pred' $(z, y)]]$

[do' $\left(\varnothing,\left[\right.\right.$ use' $\left(\varnothing\right.$, portraits $\left.\left.\left.{ }^{24}\right]\right)\right]$

CAUSE [[do' (portraits, [cover' (portraits, walls])]

CAUSE [BECOME be-on'(walls, portraits)]]

[y = Actor $][\mathrm{z}=$ Undergoer $]$

Portraits of ancestors (ACT) covered the walls (UND).

(BNCFPF W_fict_prose)

The two marked macrorole analyses in the two verbs (Spread the bread with butter / Portraits covered the walls) show the holistic interpretation attributed to the fact that the Undergoer (the surface) is seen as completely affected by the action.

\section{Conclusion}

Despite their semantic similarity, the predicates cover and spread do not participate in the same types of constructions and this has been accounted for using the methodological assumptions and analytical tools of two complementary models, the Lexical Constructional Model and Role and Reference Grammar, which have allowed us to represent their lexical meaning through the elaboration of their lexical and constructional templates. We have also provided a motivated account in terms of the cognitive processes which regulate the subsumption of their low-level lexical templates into higher-level configurations, following the LCM's assumptions, and analyzed the linking of their lexical meaning into their different syntactic realizations apply-

24 "Portraits" is presented in the logical structure because it is imposible that it becomes assigned the macrorole Undergoer, since we need first to assign the macrorole Actor. Due to the fact that the slot of the first argument of the activity is unspecified, macrorole assignment must try to find another potential candidate for Actor, which is going to be the first argument of the second activity (i.e. "portraits"). 
ing RRG analytical tools.

The notion of "spreading" places the emphasis on the process itself, and on the way or manner you distribute something over a surface, and that explains why it is often used with manner adverbs such as thinly, evenly, carefully, etc. The predicate spread typically displays the locative construction but can also go through a re-construal process externally constrained by the metonymic shift RESULT FOR ACTION which allows it to be subsumed into the with-construction, where the resultant state of distributing a substance over a surface is given prominence and has syntactic consequences which are explained as an instance of marked macrorole assignment to Undergoer. As for the entity being spread, we have seen how the intrinsic internal properties of the referent are going to condition the type of construction in which spread can participate. Thus, if the entity being spread meets the condition that it is not solid but a substance or a mass, it triggers two different assignment possibilities to Undergoer and as a result spread will occur both in the locative and in the with-constructions ( $\mathrm{He}$ spread butter on the bread / He spread the bread with butter). If, on the contrary, the entity being spread refers to a countable solid noun, the metonymic shift is not possible and only the locative construction will occur, which shows the default linking to Undergoer (They spread the maps on the floor).

On the other hand, the notion of "covering" places the emphasis on the resultant state of the location as a consequence of it being completely affected by the "covering" (holistic interpretation). The basic scenario, represented by the with-construction, shows a causal event in which an agent causes a surface to be completely covered by a substance or other entities. The re-construed form, on the other hand, is another an instance of a metonymic process that acts as licensing factor on the lexical-constructional subsumption of cover. This cognitive process allows this predicate to participate in the locatum subject construction (Portraits covered the walls) where a static event is represented and in which the instrument argument is given conceptual prominence and realized as subject (the original instigator of the action is backgrounded to the extent that it is not specified in the sentence). In syntactic terms, the different constructions in which cover participates are accounted for as examples of different macrorole assignment possibilities to two potential Actors in a causal chain, where the preposition with should be related to its instrumental use linked to logical structures which include two effectors, the second of which is an implement, and also candidate, together with the first effector, to Actor. Thus, the assignment of Actor to the first effector results in the with-construction (The other elephants covered the corpse with branches) whereas the assignment to the second effector-implement derives in the locatum subject construction (Portraits covered the walls).

\section{Works cited}

Anderson, Stephen R., 1971: "On the role of deep structure on semantic interpretation", Foundations of Language 7, 387-396.

Butler, Christopher S., 2009: "The Lexical Constructional Model: Genesis, strengths and challenges" in Christopher ButLer and Javier Martín ARISTA (eds.): Deconstructing Constructions, Amsterdam/Philadelphia: John Benjamins, 117-152. ButLer, Christopher S., 2013: "Constructions in the Lexical Constructional Model" in Brian Nolan and Elka Diedrichsen (eds.): Linking Constructions into Functional Linguistics, Amsterdam/Philadelphia: John Benjamins, 271-294.

Butler, Christopher S. and Francisco GonzalvezGarcía, 2014: Exploring Functional-Cognitive Space, Amsterdam/Philadelphia: John Benjamins.

Dowty, David R., 1979: Word Meaning and Montague Grammar, Dordrecht: Foris. 
Faber, Pamela and Ricardo MalRal Usón, 1999: Constructing a Lexicon of English Verbs, Berlin/New York: Mouton de Gruyter.

FillmoRe, Charles J., 1976: "Frame semantics and the nature of language", Annals of the New York Academy of Sciences: Conference on the Origin and Development of Language and Speech 280, 20-32. Fillmore, Charles J., 1977: "Scenes-and-frames semantics" in Antonio Zampolus (ed.): Linguistic Structures Processing. Fundamental Studies in Computer Science, Amsterdam/New York/Oxford: North Holland Publishing Company, 55-81.

FILLmoRE, Charles J., 1982: "Frame semantics" in The Linguistic Society of Korea (ed.): Linguistics in the Morning Calm, Seoul, South Korea: Hanshin Publishing Co., 111-137.

Fillmore, Charles J., 1985: "Frames and the semantics of understanding", Quaderni di Semantica 6, 222-254.

Fillmore, Charles J. and Collin F. Baker, 2010: "A Frames approach to semantic analysis" in Bernd Heine and Heiko Narrog (eds.): The Oxford Handbook of Linguistic Analysis, Oxford: Oxford University Press, 313-340.

Galera Masegosa, Alicia, 2012: "Constraints on Subsumption and Amalgamation Processes in the Lexical Constructional Model: the Case of phone and email", ATLANTIS. Journal of the Spanish Association of Anglo-American Studies 34.2, 167-184.

Goldberg, Adele, 1995: A Construction Grammar Approach to Argument Structure, Chicago: University of Chicago Press.

Goldberg, Adele, 2002: "Surface generalizations: An alternative to alternations", Cognitive Linguistics 13 (4), 1-31.

Goldberg, Adele, 2006: Constructions at Work: The Nature of Generalization in Language, Oxford: Oxford U.P.

Gonzálvez-García, Francisco, 2015: "Exploring the Lexical-Constructional Model in functional-cog- nitive space", plenary delivered at the 4th International Conference on Meaning and Knowledge Representation. Universidad Nacional de Educación a Distancia (UNED), Madrid, Spain. July 1-3, 2015.

Levin, Beth, 1993: English Verb Classes and Alternations, Chicago: University of Chicago Press.

Levin, Beth and Malka RaPPAPORT, 2005: Argument Realization, New York: Cambridge University Press.

MaIRAL Usón, Ricardo, 2015: "Constructional meaning representation within a knowledge engineering framework", Review of Cognitive Linguistics 13(1), 1-27.

Mairal Usón, Ricardo and Francisco José Ruiz de Mendoza Ibáñez, 2006: "Internal and external constraints in meaning construction: the lexicon-grammar continuum" in Teresa GIBERT and Laura Alba (eds): Estudios de Filología Inglesa: Homenaje a la Dra. Asunción Alba Pelayo, Madrid: UNED, 197-237.

Mairal Usón, Ricardo and Francisco José Ruiz de Mendoza Ibẫez, 2008: "New challenges for lexical representation within the Lexical-Constructional Model (LCM)", Revista Canaria de Estudios Ingleses 57, 137-155.

Mairal Usón, Ricardo and Francisco José Ruiz de Mendoza IbÁNez, 2009a: "Levels of description and explanation in meaning construction" in Christopher Butler and Javier Martín Arista (eds): Deconstructing Constructions, Amsterdam/Philadelphia: John Benjamins, 135-198.

Mairal Usón, Ricardo and Francisco José Ruiz de Mendoza Ibañez, 2009b: "Introduction to the Lexical Constructional Model: implications, applications and challenges", presentation given at the University of La Laguna, Spain, May 13-15, 2009.

MeL'ČUK, Igor, 1989: "Semantic primitives from the viewpoint of the Meaning-Text Linguistic Theory", Quaderni di Semantica 10 (1), 65-102. 
MeL'ČUk, Igor and Leo Wanner, 1996: "Lexical functions and lexical inheritance for emotion lexemes in German" in Leo Wanner (ed.): Recent Trends in Meaning-Text Theory, Amsterdam: John Benjamins, 209-227.

Pustejovsky, James, 1995: The Generative Lexicon, Cambridge: MIT Press.

Ruiz de Mendoza Ibáñez, Francisco José, 2013: "Meaning construction, meaning interpretation, and formal expression in The Lexical Constructional Model" in Brian Nolan and Elke Diedrichsen (eds.): Linking Constructions into Functional Linguistics, Amsterdam/Philadelphia: John Benjamins, 231-270.

Ruiz de Mendoza Ibáñez, Francisco José and Ricardo MaIRAL Usón, 2007a: "Higher-level metaphor and metonymy in meaning construction" in Radden Günter et al. (eds.): Aspects of Meaning Construction, Amsterdam/Philadelphia: John Benjamins, 33-51.

Ruiz de Mendoza Ibáñez, Francisco José and Ricardo MaIRAL Usón, 2007b: "Levels of semantic representation: Where lexicon and grammar meet", Interlingüística 17, 26-47.

Ruiz de Mendoza Ibáñez, Francisco José and Ricardo MAIRAL UsÓn, 2008: "Levels of description and constraining factors in meaning construction: An introduction to the Lexical Constructional Model", Folia Lingüística 42 (2), 355-400.

Ruiz de Mendoza Ibánezz, Francisco José and Alicia Galera Masegosa, 2014: Cognitive Modeling. A Linguistic Perspective, Amsterdam: John Benjamins.

Van Valin, Robert D. Jr. and Randy J. Lapolla, 1997: Syntax, Structure, Meaning and Function, Cambridge: Cambridge U. P.

Van Valin, Robert D. Jr., 2005: Exploring the Syntax-Semantics Interface, Cambridge: Cambridge U.P.
Vendler, Zeno, 1967[1957]: Linguistics in Philosophy, Ithaca, NY: Cornell University Press.

\section{Appendix 1}

In order to build up a list of the verbs which fit in Faber and Mairal's (1999) lexical subdomain "to put something on (the surface of) something else", different sources were consulted:

a. The Longman Lexicon of Contemporary English (1981) group words with related meanings into sets and subsets which also include definitions, examples and illustrations which help the reader grasp the similarities and differences among these related predicates. In our particular case, we could check that the verbs cover and spread are listed into the general sets "Substances, materials, objects and equipment" $(\mathrm{H})$ and "General and abstract terms (N)", and more specificaIly within the subsets "Covering and littering (H16)", "Including and containing" (H17), "Putting things on containers" (H187), "Connect (N325)", "Hiding and covering up" (N356).

b. Multiwordnet: the English Network, is a multilingual database created by Princeton University, which lists the different senses of the target word, adding synonyms, troponyms, etc., to each sense. It also provides the domain(s) (e.g. Factotum, Building, etc.) and the definition of the term together with examples.

c. Fillmore's FrameNet: the online lexical resource, created by Berkeley FrameNet Project and based on Frame Semantics, where the meaning of predicates is represented by semantic frames that describe events, relations or entities and their participants in the form of frame elements (FEs) (e.g. Instrument, Container, etc.). The different frames are illustrated by an extensive list of lexical units (LUS) belonging to each of them, and si- 
milarly, each lexical unit is also linked to an extensive list of lexically related units.

Thus, we have been able to build up the lexical subdomain "to put something on (the surface of) something else (cover/spread)" by presenting the hyponyms of each of these two predicates, and which have been organized according to the purpose of the covering, in the case of cover, or the manner or amount of substance spread, in the case of spread:

\begin{tabular}{|c|c|c|c|}
\hline \multicolumn{4}{|c|}{ COVER (HYPONYMS CLASSIFIED ACCORDING TO PURPOSE) } \\
\hline $\begin{array}{l}\text { TO MAKE } \\
\text { SOMETHING MORE } \\
\text { ATTRACTIVE }\end{array}$ & TO PROTECT IT & $\begin{array}{l}\text { NO SPECIFIC PURPOSE / COVER } \\
\text { SOMETHING COMPLETELY }\end{array}$ & $\begin{array}{l}\text { TO HIDE IT SO THAT IT } \\
\text { CANNOT BE SEEN }\end{array}$ \\
\hline $\begin{array}{l}\text { Adorn; Deck; Decorate; } \\
\text { Embellish; Encrust; } \\
\text { Festoon; Frost; Garnish; } \\
\text { Glaze; Overlay; Stud }\end{array}$ & $\begin{array}{c}\text { Mask (off); } \\
\text { Sheathe; Wax }\end{array}$ & $\begin{array}{l}\text { Blanket; Coat; Cover; Dot; Douse; } \\
\text { Dredge; Dress; Encrust; Flood; Line; } \\
\text { Film; Pave; Plate; Seal; Shellac; } \\
\text { Smother; Suffuse; Surface }\end{array}$ & $\begin{array}{l}\text { Blot out; Cloak; Enshroud; } \\
\text { Mask; Obscure; Shroud }\end{array}$ \\
\hline
\end{tabular}

\section{SPREAD (HYPONYMS CLASSIFIED ACCORDING TO MANNER} OR TYPE/AMOUNT OF SUBSTANCE SPREAD)

\begin{tabular}{|c|c|}
\hline MANNER & TYPE OF SUBSTANCE \\
/ ZERO-RELATED NOUNS
\end{tabular}

Dab; Daub; Disperse; Distribute; Litter; Scatter; Shower; Slather; Smear; Spatter; Splash; Splatter; Spread out; Sprinkle; squirt; Strew

Anoint; Birdlime; Brush; Butter; Drape;

Dust; Manure; Muck; Plaster; Rub; Spray; Spread; Overspread; Suffuse 